\title{
BLISK Fabrication by Linear Friction Welding
}

\author{
Antonio M. Mateo García \\ CIEFMA - Universitat Politècnica de Catalunya \\ Spain
}

\section{Introduction}

Aircraft engines are high-technology products, the manufacture of which involves innovative techniques. Also, aero-engines face up to the need of a continuous improving of its technical capabilities in terms of achieving higher efficiencies with regard to lower fuel consumption, enhanced reliability and safety, while simultaneously meet the restrictive environmental legislations (External Advisory Group for Aeronautics of the European Commission, 2000). Technological viability and manufacturing costs are the key factors in the successful development of new engines. Therefore, the feasibility of enhanced aeroengines depends on the achievements of R\&D activities, mainly those concerning the improvement of materials and structures.

Advanced compressor designs are critical to attain the purposes of engine manufacturers. Aircraft engines and industrial gas turbines traditionally use bladed compressor disks with individual airfoils anchored by nuts and bolts in a slotted central retainer. Nevertheless, an improvement of the component disk plus blades is the BLISK, a design where disk and blades are fabricated in a single piece. The term "BLISK" is an acronym composed of the words "blade" and "disk" (from BLaded dISK). BLISKs are also called integrated bladed rotors (IBR), meaning that blade roots and blade locating slots are no longer required. Both designs are illustrated in Figure 1.
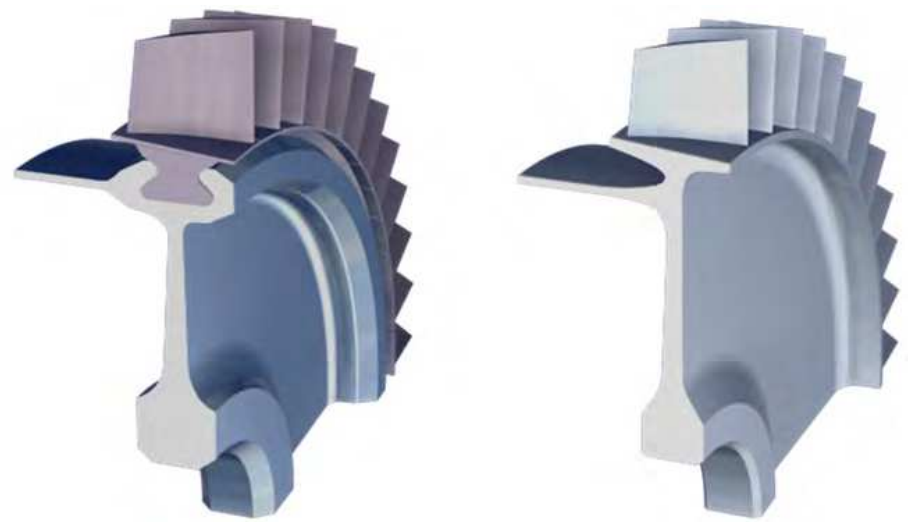

Fig. 1. Illustrations of the mechanical attachment blade-disk (left side) and of a BLISK (right side). 
BLISKs can be produced by machining from a single forged part or by welding individual blades to a disk structure. Electron-beam and inertia welding have been used for this application (Roder et al., 2003). However, these techniques are generally not recommended in critical applications concerning fatigue (Broomfield, 1986). An interesting alternative technique is linear friction welding.

Hence, this chapter is devoted to this welding process and its application to manufacture BLISKs of titanium alloys. It is obvious that for such a critical application the integrity of linear friction welds must be totally demonstrated. For that reason, extensive experimental studies were carried out to find the optimum process parameters that assure the reliability of Linear friction welding for the manufacture of BLISK. Results concerning the characterisation of the monotonic and cyclic behaviour of linear friction welds on different titanium alloys are presented. These results demonstrate that linear friction welds may offer similar tensile and fatigue properties than the corresponding base materials.

\section{Friction welding}

Friction welding technologies convert mechanical energy into heat at the joint to be welded. Coalescence of metals takes place under compressive contact of the parts involved in the joint moving relative to one another. Frictional heating occurs at the interface between the workpieces, raising the temperature of the material to a level suitable for forging. Friction welding is a solid state process as it does not cause melting of the parent material (Messler, 2004).

Friction welding techniques have significant advantages:

- No additional filler material is used.

- Neither fluxes nor gases are required.

- Efficient utilisation of the thermal energy developed.

- The process can be used to join many similar or dissimilar metal combinations. Even dissimilar materials normally not compatible for welding can be friction welded.

- Joint preparation is minimal.

- Consistent and repetitive process.

- Suitable for quantities ranging from prototype to high production.

- Environmentally friendly process: no fumes, gases or smoke generated.

- Being a solid state process, porosity and slag inclusions are eliminated.

- Creates narrow heat- affected zones.

- Friction processes are at least two and even one hundred times faster than other welding techniques.

The relative movement between the workpieces to joint can be linear or in rotation, giving rise to the diverse friction welding processes, which are described in the following subsections. Special attention is paid to the linear friction welding process.

\subsection{Rotary friction welding}

Rotary friction welding was the first of the friction processes to be developed and used commercially. There are two process variants: direct drive rotary friction welding and stored energy friction welding. The first one is the most conventional technique and usually is simply known as "friction welding". It consists in two cylindrical bars held in axial alignment. The moving bar is rotated by a motor which maintains an essentially constant 
rotational speed. The two parts are brought in contact under a pre-selected axial force and for a specified period of time. Rotation continues until achieving the temperature at which metal in the joint zone reaches the plastic state. Then, the rotating bar is stopped while the pressure is either maintained or increased to consolidate the joint. Figure 2 illustrates the stages of this process.

The other variant of rotary friction welding is the stored energy process, more often called "inertia welding". The rotating component is attached to a flywheel which is accelerated by a motor until a preset rotation speed is reached. At this point, drive to the flywheel is cut and the rotating flywheel, with stored energy, is forced against the stationary component. The resultant braking action generates the required heat for welding. Sometimes additional pressure is provided to complete the weld.
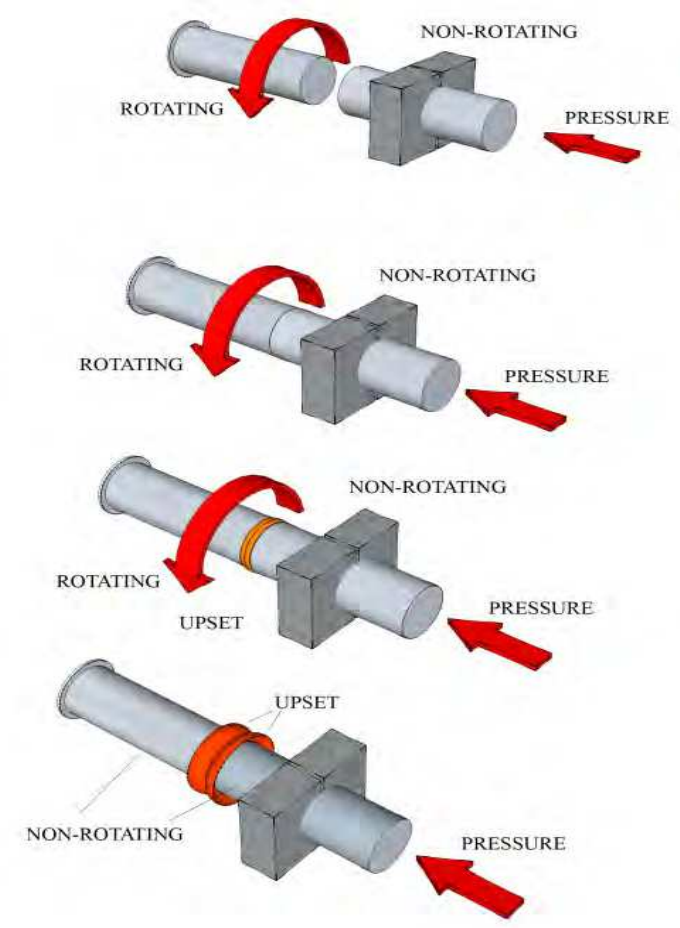

Fig. 2. Illustration of the stages of the direct drive rotary friction welding process.

The industrial acceptance of those benefits, together with the high quality obtained when using conventional rotary friction welding to produce joints in round section metallic components, led in the 1980's to the development of other welding techniques based on friction, such as friction stir welding and linear friction welding. These new friction welding processes allow joining non-round or complex geometry components.

\subsection{Friction stir welding}

Friction Stir Welding (FSW) is considered to be the most significant development in metal joining in the last decades of $20^{\text {th }}$ century. Figure 3 shows the different stages of this process. 
Essentially, a cylindrical non-consumable spinning tool is rotated and slowly plunged into the joint line between two pieces of sheet or plate material, which are butted together. The parts have to be clamped onto a backing bar in a manner that prevents the abutting joint faces from being forced apart. Frictional heat is generated between the wear resistant welding tool and the material of the workpieces. This heat causes the latter to soften without reaching the melting point. As the tool traverses the weld joint, it extrudes material in a distinctive flow pattern and forges the material in its wake. The resulting solid phase bond joins the two pieces into one. FSW can be regarded as a solid phase keyhole welding technique since a hole to accommodate the probe is generated, then filled during the welding sequence. Nowadays, FSW is used to join high-strength aerospace aluminium alloys with astounding success (Threadgill et al., 2009). For example, in the Eclipse 500 aircraft, now in production, $60 \%$ of the rivets are replaced by FSW. This fact has naturally stimulated exploration of its applicability to other alloys, such as copper (Won-Bae \& SeungBoo, 2004), titanium, magnesium and nickel (Mishra \& Mahoney, 2007) and attempts have even been made to investigate it for the joining of polymers (Strand, 2003). In the particular case of steels, FSW tools would have to go through temperatures higher than $800^{\circ} \mathrm{C}$ in order to achieve a sufficiently plasticised steel to permit the material flow to enable a sound weld to be fabricated. Cost effective tool materials which survive such conditions for extended service remain to be developed (Bhadeshia \& DebRoy, 2009).

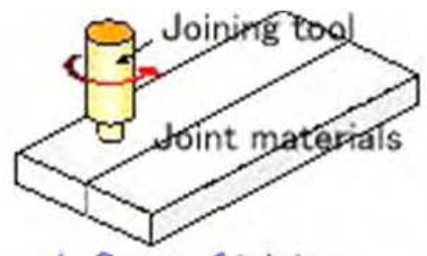

1. Start of joining

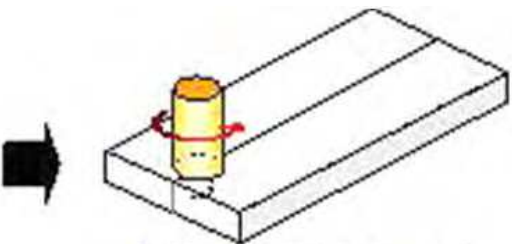

2. Insert joining tool

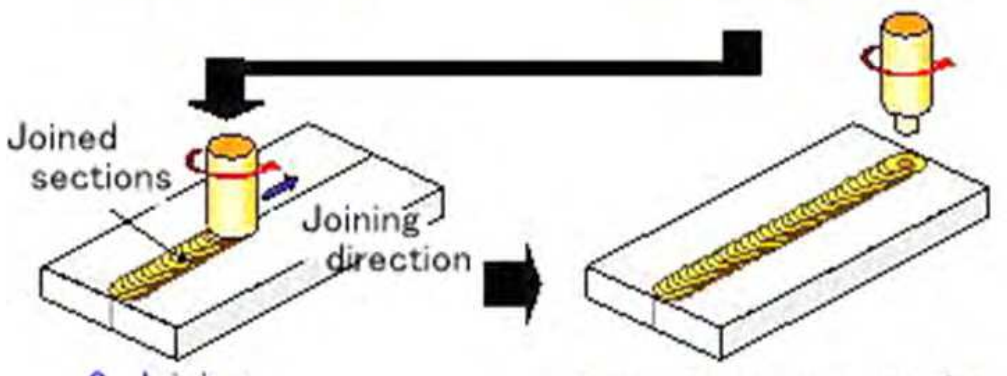

3. Joining

4. Pull away joining tool (end)

Fig. 3. Illustration of the stages of the friction stir welding process.

\subsection{Linear friction welding}

A British patent of The Caterpillar Tractor Co. described in 1969 a linear reciprocating equipment for welding steel (Kauzlarich et al., 1969), although no further information was published on this topic during the following decade. In the early 1980s, TWI (The Welding Institute) designed and built a prototype of electro-mechanical machine and demonstrated the viability of the Linear Friction Welding (LFW) technique for metals. Similar machines 
are now located at industrial plants of aircraft engine manufacturers in Europe and USA, such as MTU Aero Engines, Rolls Royce, Pratt \& Whitney and General Electric, where it has proved to be an ideal process for joining turbine blades to disks. For this use, the elevated value-added cost of the components justifies the high price of a LFW machine. Nevertheless, the introduction of this welding technique to other more conventional applications requires novel solutions, which are still in development, principally to reduce the cost of the equipment (Nunn, 2005).

Like all the other friction welding techniques, LFW is able to join materials below their melting temperature. However, in LFW a linear reciprocating motion is the responsible of rubbing one component across the face of a second rigidly clamped part using an axial forging pressure, as depicted in Figure 4. The amplitude of the oscillating motion is small ( 1 to $3 \mathrm{~mm}$ ) and the frequency uses to be in the range of 25 to $125 \mathrm{~Hz}$. The maximum axial welding stress is around $100 \mathrm{MPa}$ when titanium alloys are welded and it increases to $450 \mathrm{MPa}$ for nickel pieces.

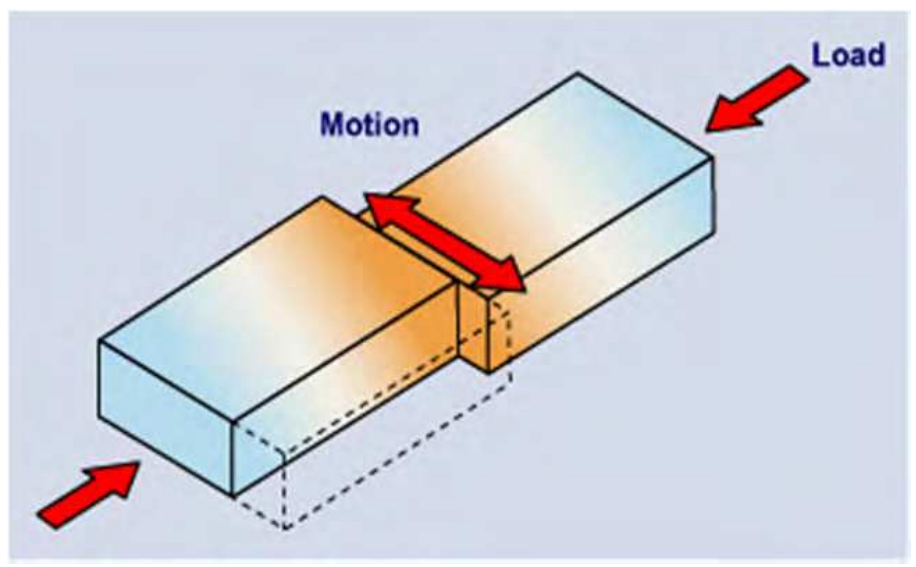

Fig. 4. Illustration of the motion of the parts in the linear friction welding process.

\subsubsection{Linear friction welding stages}

LFW process can be divided in four distinct stages, as shown in Figure 5. These stages were described in detail by Vairis \& Frost (1998).

- $\quad$ Stage I: In the initial phase, both parts are brought in contact under pressure. The two surfaces rest on asperities and heat is generated from solid friction. The true contact area increases significantly throughout this phase due to asperity wear. There is no axial shortening of the specimens at this stage. If the rubbing speed is too low for a given axial force, insufficient frictional heat will be generated to compensate for the conduction and radiation losses, which will lead to insufficient thermal softening and the next phase will not follow.

- Stage II: In the transition phase, large wear particles begin to be expelled from the interface. The true contact area is considered to be $100 \%$ of the cross-sectional area. Both workpieces are heated by the friction and the material reaches a plastic state. The soft plasticised layer formed between the two materials is no longer able to support the axial load. 
- $\quad$ Stage III: In the equilibrium phase, heat generated is conducted away from the interface and a plastic zone develops. The oscillatory movement extrudes material from the plasticised layer giving rise to flash formation. As a result, axial shortening of the parts takes place. If the temperature increases excessively in one part of the interface away from the centre line of oscillation, the plasticised layer becomes thicker in that section causing more plastic material to be extruded.

- Stage IV: In the deceleration phase, to complete the working cycle the oscillation amplitude decays until the total stop in times ranging from 0.2 to 1 seconds and the components are placed into perfect alignment. The decay rate is an important parameter because longer decay periods are less severe and assist bond formation. Finally, the axial welding pressure is maintained or increased to consolidate the joint. This pressure is usually called forge pressure.

The total cycle is very short, of the order of a few seconds.

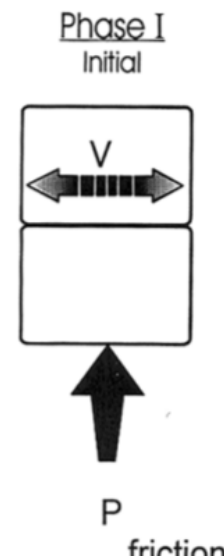

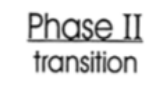

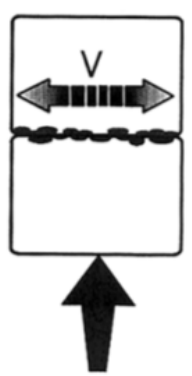

$\mathrm{P}$

friction

Phase III equilibrium

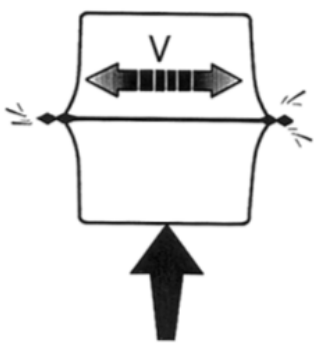

$\mathrm{P}$ friction

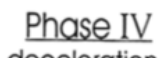

deceleration

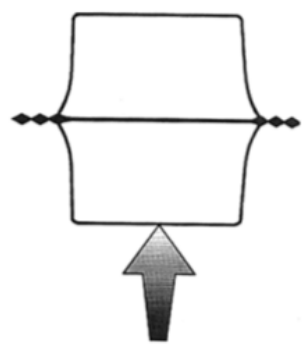

$\mathrm{P}$

forging

Fig. 5. Illustration of the four phases of the linear friction welding process.

\subsubsection{Linear friction welding applications}

Despite LFW is a relatively new welding process, it has demonstrated to be efficient to join many different metals, including steels, mainly high strength and stainless steels (Bhamji et al., 2010), aluminium (Ceschini, 2010), nickel (Mary \& Jahazi, 2006) and titanium alloys (Wilhem et al., 1995). Even in the cases of intermetallic alloys (Threadgill, 1995), metal matrix composites (Harvey et al., 1995) and dissimilar joints, for example welding copper to aluminium for electrical conductors (Threadgill, 2011), LFW has been yet successfully employed.

LFW technique development has been always linked to aerospace industry. Its first important industrial use was for repairing damaged blades of aircraft engines made in nickel superalloys and titanium alloys. In this application, LFW process showed that it is particularly appropriate for welding titanium. The large affinity of titanium for oxygen, nitrogen and hydrogen makes that fusion welding of these alloys must be carried out under inert gas atmosphere. Conversely, LFW avoids the formation of liquid phase and can consequently be done in air. The next logical step was to expand LFW use to titanium BLISK production. 


\section{BLISK production}

BLISK is one of the most original components in modern aero-engines. First used in small engines for helicopters, BLISK was introduced in the 1980's for military airplanes engines, and it is rapidly gaining position in commercial turbofan and turboprop engines. This is due to its advantages, such as:

- $\quad$ weight saving (usually as much as $20-30 \%$ ): resulting from the elimination of blade roots and disk lugs;

- $\quad$ high aerodynamic efficiency: because BLISK diminishes leakage flows;

- $\quad$ eradication of the blade/disk attachment, whose deterioration by fretting fatigue is very often the life limiting feature.

Of course, BLISK has disadvantages too. The main one is the laborious, and then expensive, manufacturing and repairing processes. Also, an exhaustive quality control is required to ensure reliable performance. Development efforts are currently trying to mitigate these drawbacks.

As it was commented in the introduction of this chapter, BLISKs can be produced by machining from a single forging or by bonding single blades to a disk-like structure. Depending on the material and also on the design, factors that in turn depend on its location in the engine, each BLISK has its particularities that determine the selection of the manufacturing process. A complete description of the optimisation process for BLISK design and manufacture is given by Bußmann et al. (2005).

In the case of BLISKs produced by machining, there are also two possible paths: milling the entire airfoil or using electrochemical material removal processes. The first technique, illustrated in Figure 6, is used for medium and small size blades.

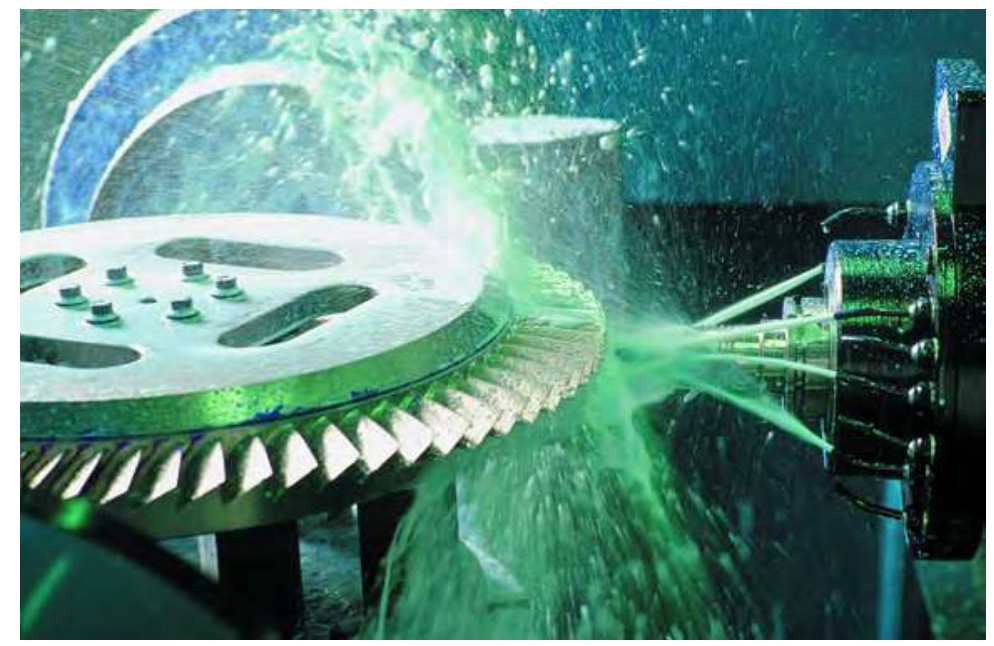

Fig. 6. Photograph of BLISK machining by high-speed milling (courtesy of MTU AeroEngines).

In the case of low pressure compressor stages, where the length of the blades is a significant proportion of the diameter of the total component (disk + blades), machining the BLISK from a single forged raw part is a costly and inefficient way. Therefore, welding the blades 
to the disk becomes a more effective approach. Figure 7 shows the three first stages of the low pressure compressor of an EJ200 aero-engine. This engine is fabricated by using the BLISK technology.

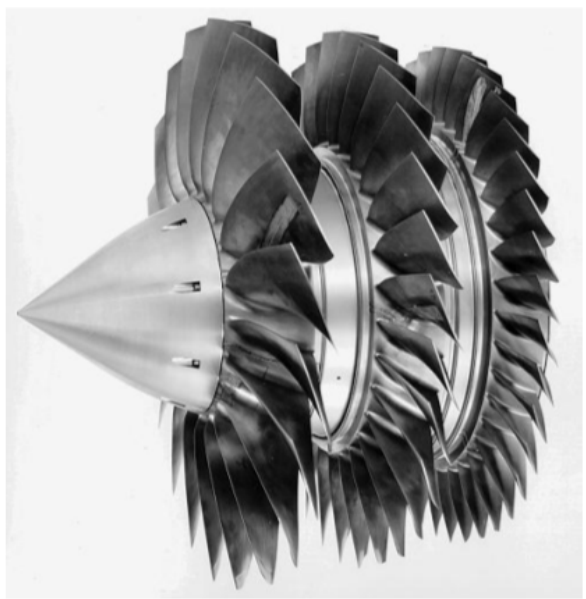

Fig. 7. Low pressure compressor of the Eurojet EJ200 turbofan engine fabricated with the BLISK technology.

Full qualification for aero-engine application has been achieved for LFW manufacturing route. Design and manufacturing advantages derived of the fabrication of BLISKs by LFW in front of other processing routes are:

- High integrity welding technique;

- Low distorsion of the welded parts;

- Heat affected zone of very fine grain;

- Porosity free;

- Possible welding of dissimilar alloys for disk and for blades;

- Fabrication of large diameter BLISKs without the need for huge forged pancakes;

- Tolerances in position and angles of welded blades are very accurate.

\section{Titanium alloys for BLISKs}

A modern commercial aircraft is designed to fly over 60.000 hours during its 30 -year life, with over 20.000 flights. This amazing capacity is for the most part a result of the high performance materials used in both the airframe and propulsion systems. One of those high performance materials is titanium.

The aerospace industry consumes $50 \%$ of the world's annual titanium production that was of almost 218.000 tonnes in 2010. Ti alloys make up 20\% of the weight of modern Jumbos. For example, the new generation of huge commercial airplanes, i.e. Airbus A380 and Boeing 787 Dreamliner, include between 130 and 150 tons of titanium components per unit. Military aircraft demand also drives titanium usage. On the other hand, nowadays the range of $\mathrm{Ti}$ alloys available is very wide and this is a reflect of its growing use outside the aerospace sector, for example in chemical, marine, biomedical, automotive and other industrial applications. 
In the case of the propulsion systems, selection of materials is based on their resistance to a combination of high loads and temperatures, together with extremely high safety levels. Typical engine materials are characterised by high specific strength values, i.e. strength divided by density, together with excellent reproducibility of mechanical properties. In this perspective, the development of modern gas turbine engines is mainly based on nickelbased superalloys, but Ti alloys also figure significantly. Around 33\% of the weight for a commercial aircraft engine is due to the use of $\mathrm{Ti}$ alloys. For military engines this value approaches $50 \%$. The main properties that justified the success of $\mathrm{Ti}$ alloys in aero-engines over the last five decades are their high specific strength (thanks to their low density of $\left.4.5 \mathrm{~g} / \mathrm{cm}^{3}\right)$, together with good corrosion resistance and weldability. However, titanium has a limited temperature capability, mainly due to oxidation constrains; therefore, Ti alloys are used for parts under moderate temperatures (i.e. fan and compressor) whereas nickel alloys are preferred for the high temperature regions (i.e. last stages of the high pressure compressor and turbines).

Titanium has two allotropic forms: alpha $(\alpha)$ and beta $(\beta)$. $\alpha$ refers to hexagonal closed packed crystal structure, while $\beta$ denotes cubic centred body structure. $\alpha$ and $\beta$ are the basis for the commonly accepted classification of Ti alloys in four types: $\alpha$, near- $\alpha, \alpha+\beta$ and $\beta$. These categories denote the microstructure after processing and heat treatment. In general, $\alpha$ and near- $\alpha$ alloys have better creep and oxidation resistance, $\alpha+\beta$ alloys posses an excellent combination of strength and ductility, whereas $\beta$ alloys have good formability and may be hardened to reach high strength levels (Donachie, 2000).

For low pressure compressors and the first stage of the high pressure compressor, where maximum operating temperature is $550^{\circ} \mathrm{C}$, principally $\alpha+\beta$ Ti alloys are used. Typical titanium alloys in fan and compressor disks for civil aero-engines are Ti-6Al-4V (Ti-64) for applications up to $300^{\circ} \mathrm{C}$ and Ti-6Al-2Sn-4Zr-2Mo-0.15Si (Ti-6242) for service up to $480^{\circ} \mathrm{C}$. The first alloy is the standard $\alpha+\beta$ alloy and the later one is a near- $\beta$ alloy.

Ti-6Al-2Sn-4Zr-6Mo (Ti-6246) and Ti-5Al-2Sn-2Zr-4Mo-4Cr (Ti-17) are the only approved and certified (very important point in aero-engine business) high strength $\alpha+\beta$-titanium alloys. They are considered high strength alloys because offer $10-20 \%$ higher tensile strength than the typical Ti-64 and Ti-6242, and even higher values can be obtained when used in $\beta$ processed conditions. This high tensile resistance is maintained up to $300^{\circ} \mathrm{C}$ for Ti-17 and up to $450^{\circ} \mathrm{C}$ for Ti- 6246 .

On the other hand, the design constrains for disks and blades are different. Whereas high tensile strength and low cycle fatigue resistance are the most relevant properties for disk materials, high cycle fatigue and creep resistance are the main desired characteristics for blades. From this perspective, a possibility for optimisation of compressor performance would be to manufacture stages with a "disk-optimised" material condition for the disk combined with a "blade-optimised" material condition for the blades. Depending on the position in the compressor, a certain combination may be the optimum, whereas at another position another combination would be the right choice. For example, in the temperature regime from 430 to $520^{\circ} \mathrm{C}$, an excellent combination would be a $\beta$-processed high strength Ti alloy (Ti-6246 or Ti-17) for the disk whit the typical Ti-64 or Ti-6242 alloys for the blades.

BLISKs produced by machining must comprise one single material, with the same microstructure for disks and blades, the specific condition being mostly optimised for the disks. In opposition, the use of the welding to manufacture BLISK opens this innovative possibility of joining dissimilar alloys, choosing the most convenient alloys and microstructures for each component, i.e. for disks and for blades. 


\section{DUTIFRISK project}

It is expected that BLISKs with optimised material conditions, such as it was described in the section 4 of this chapter, would offer an improved in-service performance. But this will be true only if the mechanical properties of the weld-zone are good enough too. Nevertheless, these properties are difficult to predict because the microstructure produced by joining two different alloys by LFW may be very different of the base materials. Therefore, an ambitious European R\&D Program was envisaged with the objective of characterizing the microstructure on the weld-zone and to determine the mechanical response of different combinations of titanium alloys selected to optimise BLISK performance. This research project, called "Dual Material Titanium Alloy Friction Welded BLISK", acronym DUTIFRISK, was carried out during 54 months, from April 2002 to September 2006. MTU Aero Engines (Germany) was the project coordinator, although another aero-engines producer, SNECMA Moteurs (France), contributed to the project too. Other participants in the project were: Böhler Schmiedetechnik (Austria), as a Ti alloys supplier; TWI (England), as the main LFW expert centre; ENSMA-CNRS (France) and CIEFMA-UPC (Spain), as research centres with large experience on materials science and technology.

\subsection{Objectives}

The following tasks, among others, were performed within the DUTIFRISK project:

- Production and characterisation in terms of relevant basic mechanical properties of the titanium alloys used in the project;

- Manufacture, testing and assessment of linear friction welded trial joints to optimise welding parameters;

- Manufacture, detailed testing and assessment of linear friction welded joints;

- Production and validation of a demonstrator BLISK.

The exploration for optimised linear friction welding parameters was developed on specimen scale size for various combinations of high strength titanium alloys (Ti-6246 and Ti-17) as disk-material and various $\alpha+\beta$-titanium alloys (Ti-6242, Ti-64, Ti-6246) as bladematerials. Post-weld heat-treatments were transferred from other welding processes for similar material combinations.

The exhaustive mechanical evaluation of the welds included different types of tests: standard tests (tensile, creep/creep rupture, low-cycle and high-cycle fatigue testing), standard tests adapted to evaluate the weld area properties (fracture toughness and fatigue crack propagation testing) and also specific "new" tests, such as micro-tensile test and Young's modulus measurement. A huge quantity of results was produced during the project. A few of them have been already published (Corzo et al., 2006, 2007; Mateo et. al., 2009; Roder at al., 2008). In subsection 5.2 some selected results, mainly concerning Ti-6246 alloy, are shown and the main conclusions are commented.

The final step of DUTIFRISK project was the production and testing of BLISK demonstrators. Their validation is the key point to prove the transferability of the results obtained on specimen scale to production scale.

\subsection{Base materials}

As previously explained in Section $4, \alpha+\beta$ Ti-6246 is one of the titanium alloys which are particularly suitable for compressor disks, whereas the same alloy with $\alpha+\beta$ microstructure 
would be adequate for blades. Ti-6246 for DUTIFRISK project was produced by Böhler Schmiedetechnik following different fabrication processes depending whether the material was designated to produce the disk or it was for the blades, in order to achieve optimised microstructural characteristics for each part.

Ti-6246 for the disk was produced by die-forging. One of the die-forged disks is shown in Figure 8. It was forged in the $\beta$-region, i.e. at temperatures higher than the $\beta$-transus $\left(945^{\circ} \mathrm{C}\right)$. Heat treatment consisted in a solution annealing at $915^{\circ} \mathrm{C}$ for 2 hours, with a forced air cooling, and finally an ageing at $595^{\circ} \mathrm{C}$ for 8 hours with air cooling.

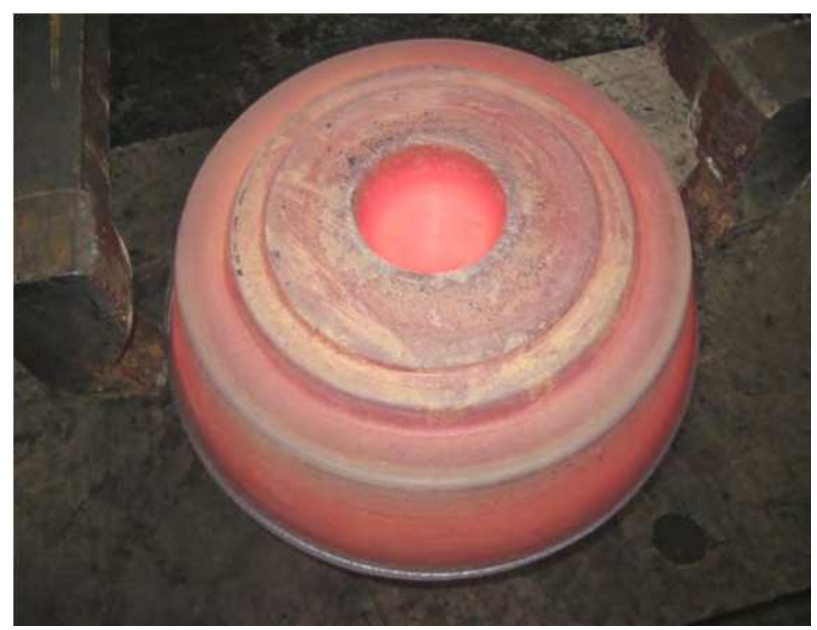

Fig. 8. Ti-6246 die-forged disk in the as-forged condition (courtesy by BSTG)

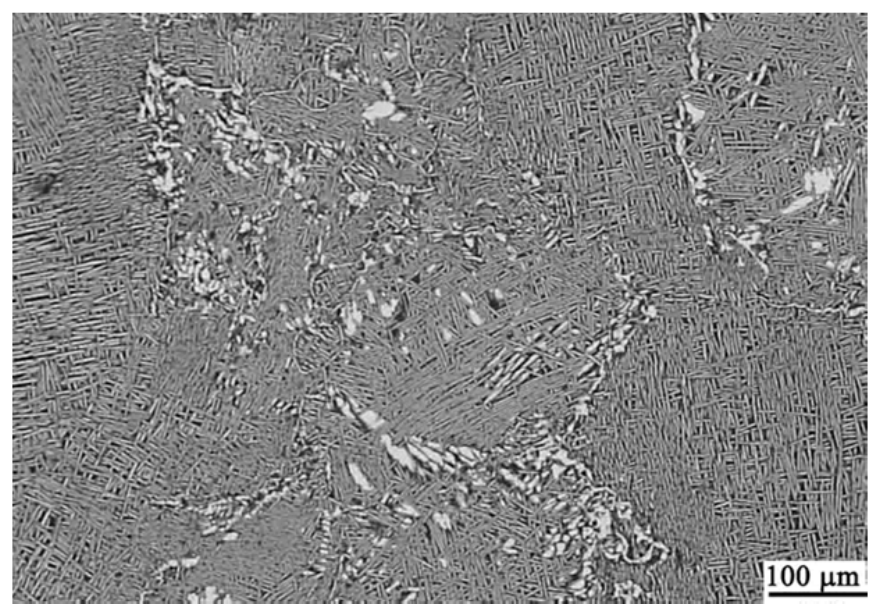

Fig. 9. Microstructure of $\beta$-forged Ti-6246.

Microstructural characterisation was carried out by optical microscopy and SEM (Scanning Electron Microscopy). Ti-6246 for the disks exhibits the typical aspect of a $\beta$-forged 
microstructure, with platelet-like $\alpha_{\mathrm{p}}$-formation and the desired discontinuous $\alpha$-layer along the grain boundaries (Figure 9). This type of microstructure is often designated as lamellar. The age hardening treatment produces $\alpha_{\text {sec }}$-platelets in the $\beta$-matrix, between the $\alpha_{\mathrm{p}}$-plates, but they are only visible at high magnification.

In the case of Ti-6246 for the blades, slabs were forged in the $\alpha+\beta$-field (around $900^{\circ} \mathrm{C}$ ), then annealed and aged following the same treatment than the disk material. The appearance of the $(\alpha+\beta)$-forged alloy, with its typical bi-modal microstructure, can be observed in Figure 10. It is composed by globular $\alpha_{\mathrm{p}}$-particles embedded in a fine lamellar $\alpha+\beta$ matrix. The $\alpha_{\mathrm{p}}$ content is around $28 \% \mathrm{vol}$. and the mean size of the nodules is $15 \mu \mathrm{m}$.

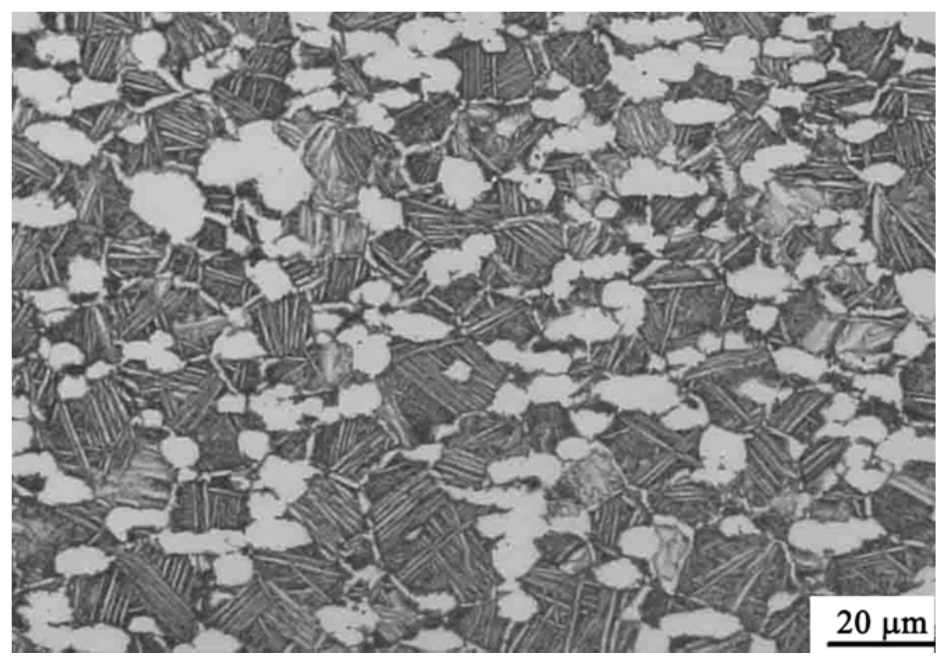

Fig. 10. Microstructure of $\alpha+\beta$-forged Ti-6246.

\subsection{Linear friction welds}

Blocks of $60 \times 36 \times 15 \mathrm{~mm}$ were cut from the disks and slabs and welded using an electromechanical LFW machine instrumented to monitor and record the time dependant evolution of all significant process parameters. The appearance after welding is shown in Figure 11. A post-weld heat treatment at $620{ }^{\circ} \mathrm{C}$ during 4 hours in vacuum was always performed. Those blocks were used for microstructural and mechanical characterisation of the different welds.

Cross sections of the welds were prepared for microstructural survey. An image corresponding to a transversal section is shown in Figure 12. The narrow weld-zone is clearly seen. Its apparent width is around $1 \mathrm{~mm}$ in the centre and wider at the extremes of the joint.

The microstructure of LFWs was analysed by SEM. Figure 13 is a global view of the weld centre and the heat affected zone where the evolution of both microstructures, i.e. $\alpha+\beta$ and $\beta$, when approaching the weld line is clearly appreciated. 


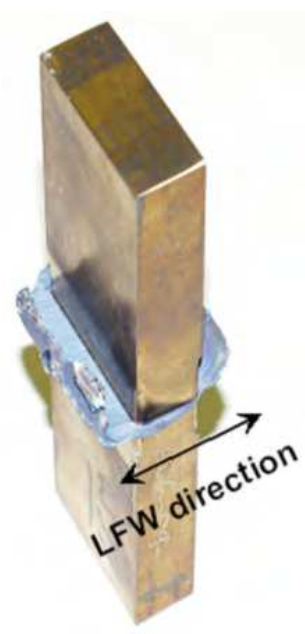

Fig. 11. Photograph of a welded block.

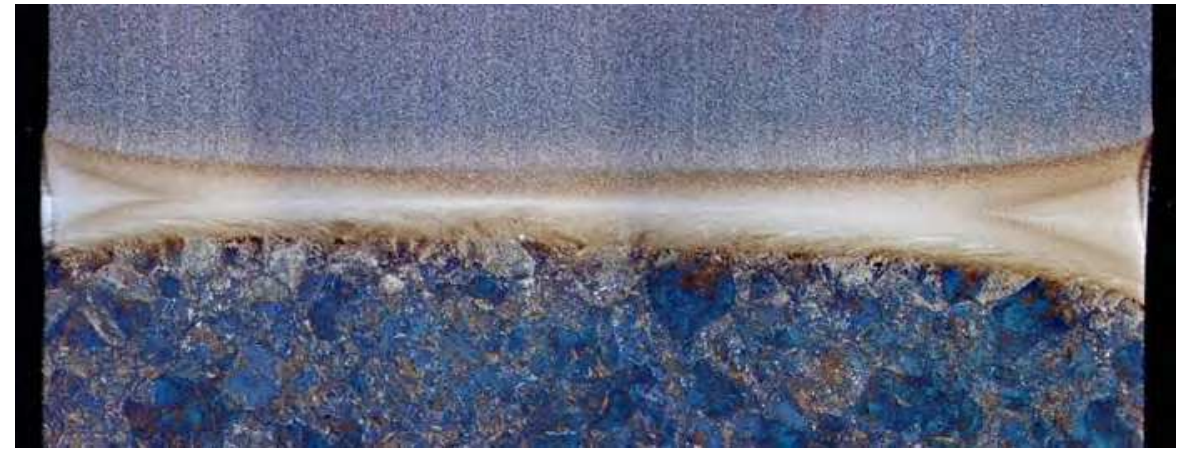

Fig. 12. Macrograph of the cross section of a weld (blade material in the upper part and disk material in the lower part).

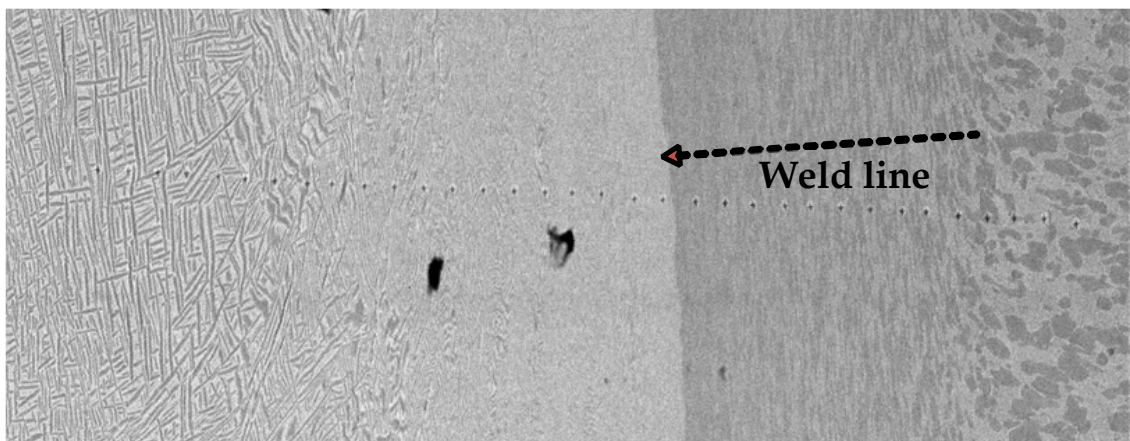

Fig. 13. Microstructure in the weld and heat affected zone. Blade $(\alpha+\beta-T i-6246)$ at the right side and disk ( $\beta$-Ti-6246) at the left one. 
Microstructural evolution was analysed at different positions of the weld line. In $\beta-$ Ti-6246 alloy, a distortion of the $\alpha$-lamellae is first observed and then the size of lamellas is progressively reduced as the weld zone is approached (Figure 14).

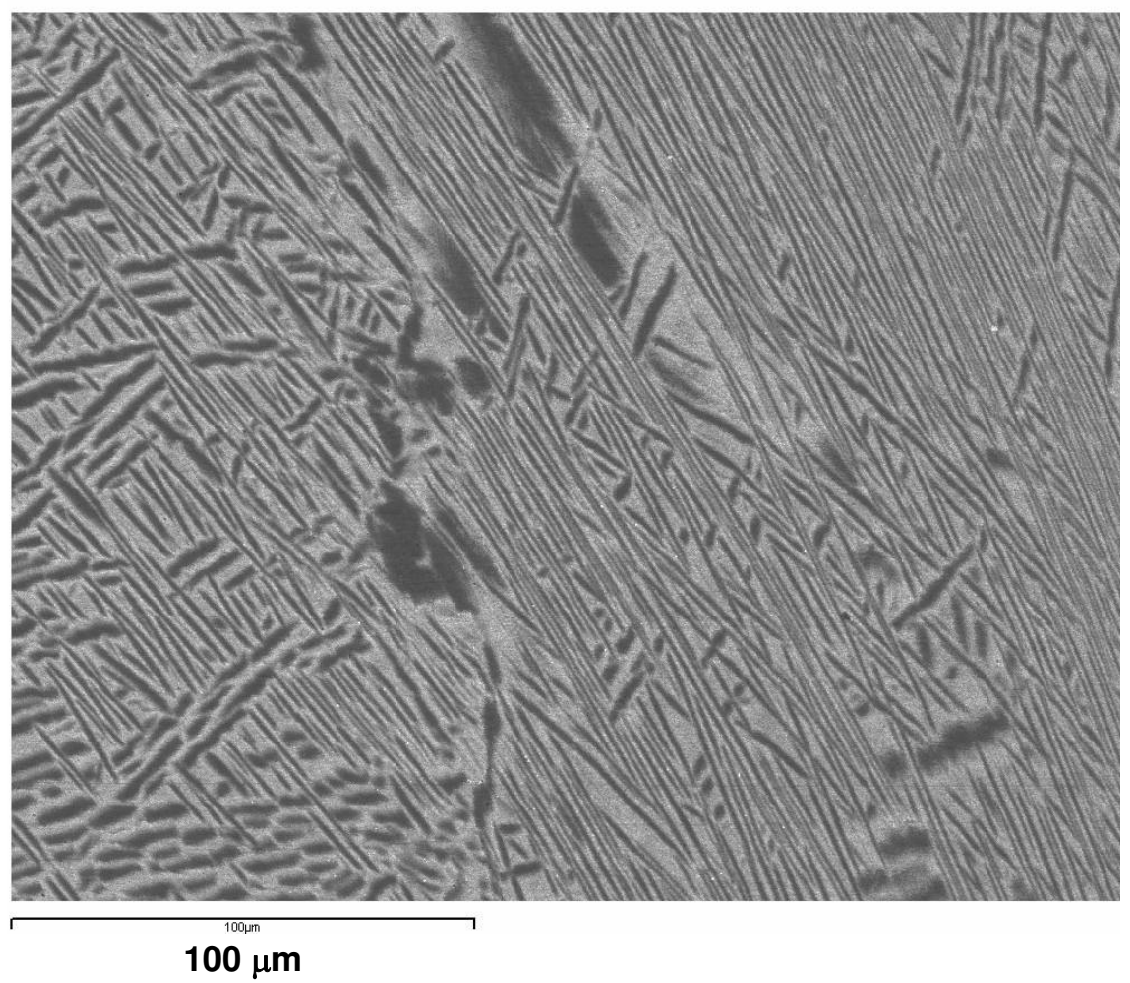

Fig. 14. Microstructure in the disk side when approaching the weld centre (situated to the right side).

Directly in the weld plane the microstructure is too fine to be resolved by conventional SEM. Therefore, more powerful techniques, such as FE-SEM (Field Emission) and TEM (Transmission Electron Microscopy), were used. Figure 15 shows the microstructure at both sides of the weld line, whereas Figure 16 is an even higher magnification picture of the weld centre where grains of nanometric size are observed. This very fine microstructure is characteristic of LFW and evolves from the fact that the temperature during the process exceeds the $\beta$-transus in a small volume of material and the cooling rate for this small volume is very high (Helm \& Lutjering, 1999).

In the blade side, $\alpha+\beta$ Ti-6246 microstructure close to the weld zone shows highly deformed $\alpha_{p}$ nodules, elongated following the friction movement direction (Figure 17). Far away, the microstructures changes gradually towards that corresponding to the base materials, according to the decreasing temperature and plastic deformations reached at each point. 


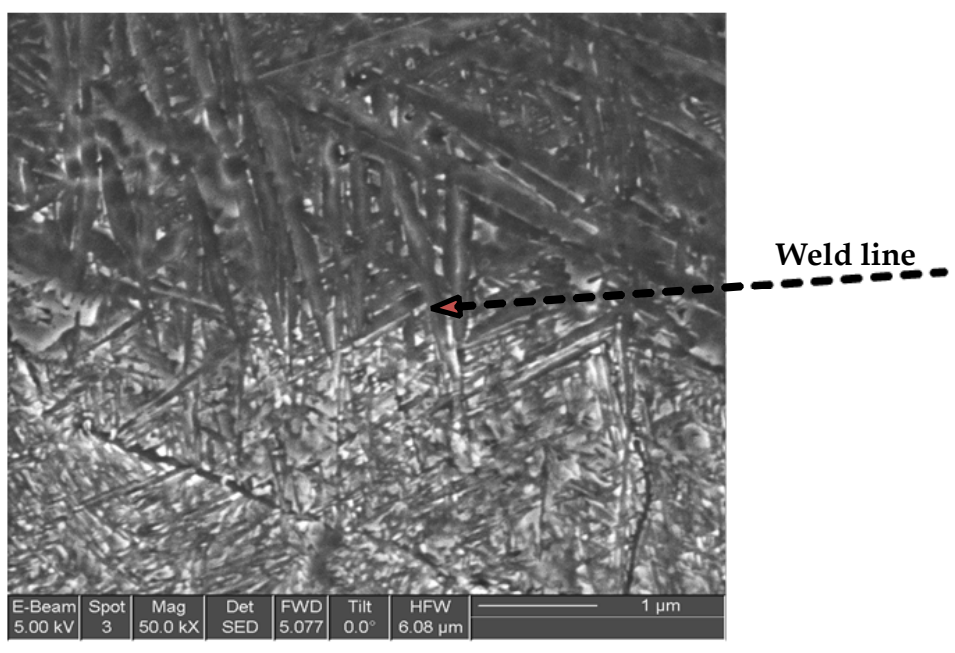

Fig. 15. Microstructure in the weld zone observed by FE-SEM. Disk material is in the upper part of the image and blade material in the lower one.

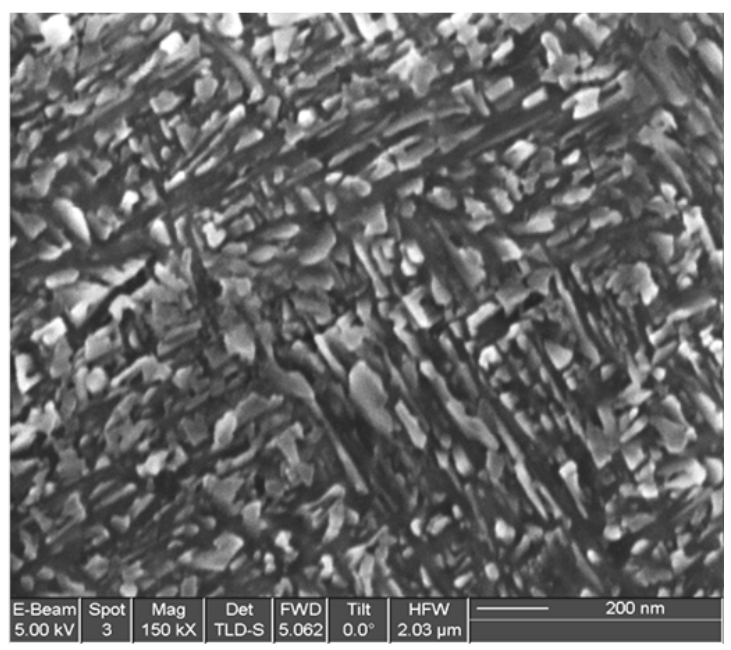

Fig. 16. Microstructure in the weld centre observed by FE-SEM. 


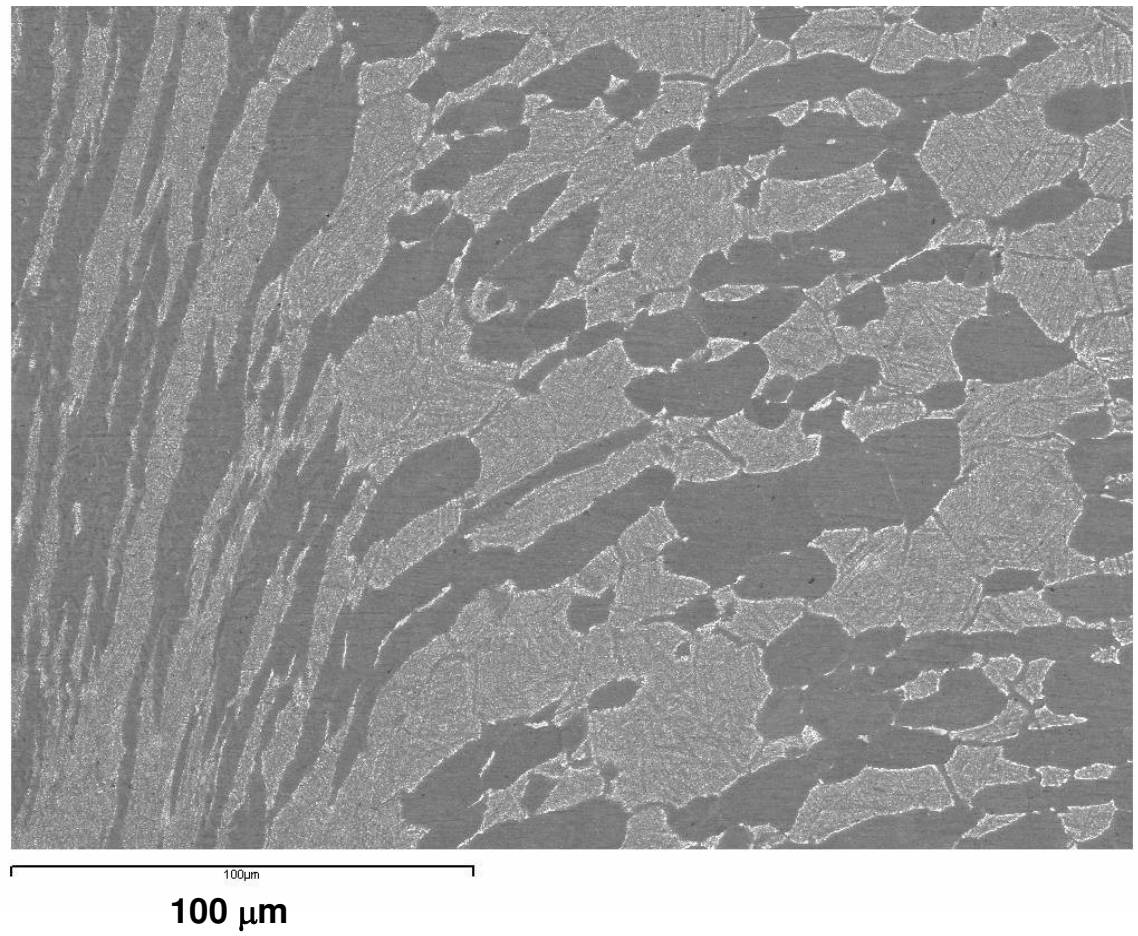

Fig. 17. Microstructure in the blade side when approaching the weld centre (situated to the left side).

\subsection{Mechanical characterisation}

The following subsections present the results of the different mechanical tests performed to evaluate both the monotonic and cyclic properties of LFW for BLISK manufacturing on titanium alloys.

\subsubsection{Hardness profiles}

The first step for the characterization of the mechanical response of the welds was measuring their hardness profiles. Loads of $0.5 \mathrm{~kg}$ were applied with a Vickers indenter. The profiles showed in Figure 18 correspond to the central part of the specimen, where the heat affected zone is narrower, and to a near flash zone.

\subsubsection{Tensile properties}

Concerning tensile testing of base materials, it was conducted on cylindrical specimens of 6 $\mathrm{mm}$ in diameter. The same geometry was used to machine specimens from the welded blocks, always with the load axis perpendicular to the joining plane of the weld. All tests were performed under displacement control at a rate of $2 \mathrm{~mm} / \mathrm{min}$ and at least two specimens for condition were tested. Table 1 summarizes the main results of tensile tests. 


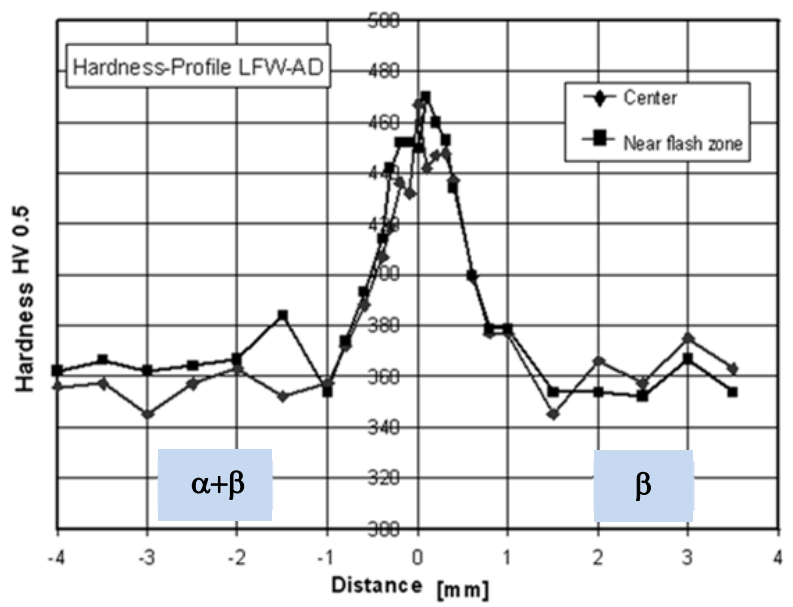

Fig. 18. Hardness profile of one of the welds.

Table 1 results evidence that both base material conditions have similar strength values, being slightly higher for the $\beta$-forged alloy. All of them are in the typical range reported for Ti-6246 (Donachie, 2000). Tensile properties of the welds are close to those obtained for bimodal $\alpha+\beta$ Ti-6246, which is the specimen side where the fracture occurred. It is important to note that fracture never took place by the weld zone. Moreover, it always began in the blade alloy side, at a distance of at least $10 \mathrm{~mm}$ from the centre of the weld, as shown in Figure 19.

\begin{tabular}{|c|c|c|c|}
\hline Alloy & $\sigma_{\mathrm{ys}}(\mathrm{MPa})$ & $\sigma_{\text {uts }}(\mathrm{MPa})$ & Elongation $(\%)$ \\
\hline$\beta$ Ti-6246 & 1051 & 1155 & 13 \\
\hline$\alpha+\beta$ Ti-6246 & 1044 & 1125 & 18 \\
\hline Welds & 1030 & 1078 & 19 \\
\hline
\end{tabular}

Table 1. Tensile testing results.

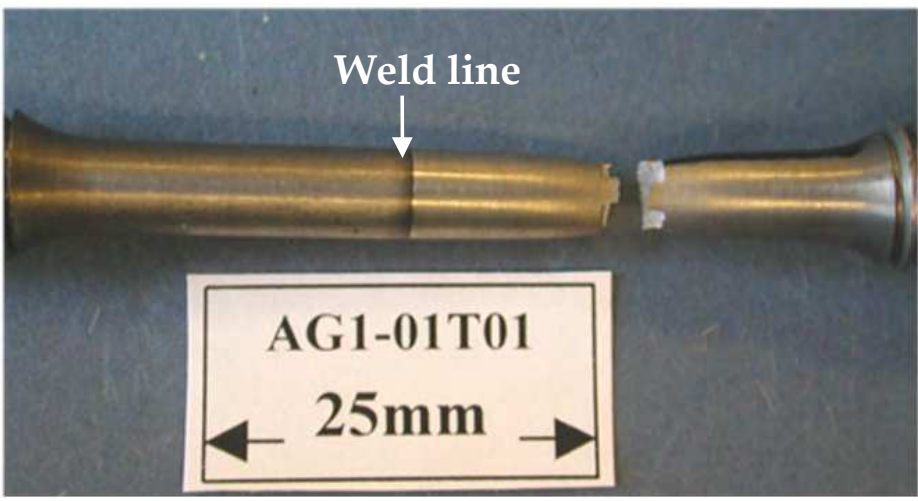

Fig. 19. Photograph of a tested tensile specimen. Note the fracture at the right side, far from the weld line. 


\subsubsection{Fatigue behaviour}

The behaviour in the HCF (High Cycle Fatigue) regime of base Ti alloys and welded specimens was compared. Fatigue testing was carried out at a load ratio R of 0.1. Smooth specimens, carefully polished, with $4 \mathrm{~mm}$ in diameter and $35 \mathrm{~mm}$ of gauge length were used. The endurance limit was considered for $2 \times 10^{7}$ cycles. Again, fracture never took place by the weld zone. Figure 20 plots the S-N curves obtained, in terms of maximum stress. Both Ti-6246 conditions, i.e. lamellar and bimodal microstructures, exhibit similar HCF behaviour. Red points corresponding to friction welded specimens are located at comparable and even higher stress values than base Ti alloys. However, the limited number of tested specimens, together with the high scatter on the results, makes difficult to fix a fatigue limit. Analogous fatigue behaviour appears in a published work dealing with different titanium alloys (Wisbey, 1999).

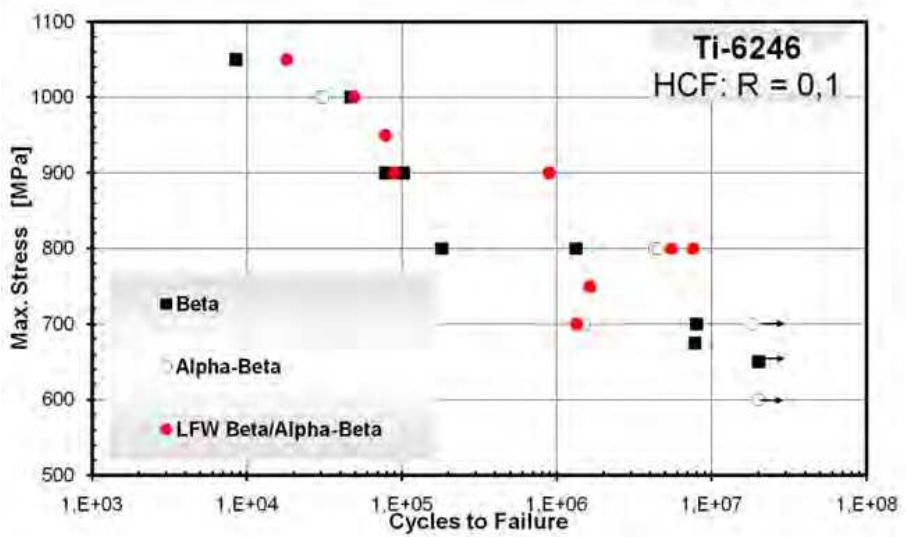

Fig. 20. HCF results for base materials and welds.

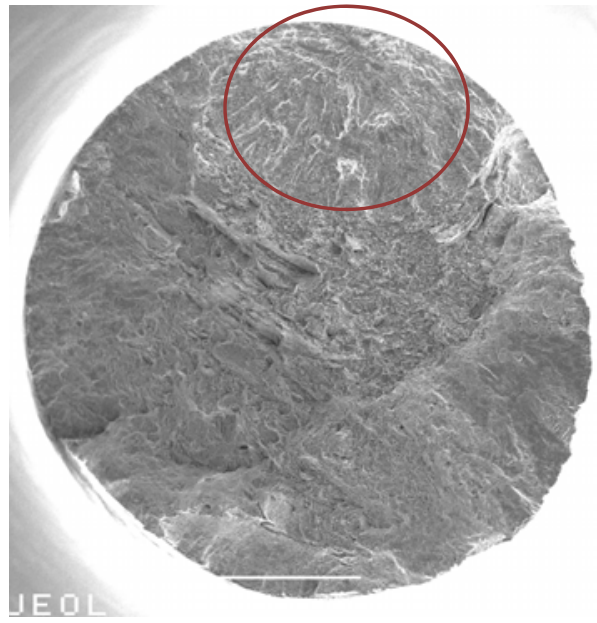

Fig. 21. Fracture surface of welded specimen tested at $\sigma_{\max }=800 \mathrm{MPa}$ and failed after $6 \times 10^{6}$ cycles. Circle indicates the origin of fatigue fracture. 
In order to study crack nucleation mechanisms, an exhaustive analysis of fracture surfaces of the specimens tested in HCF was carried out. This study revealed significant features:

- failures took place sometimes in the disk side and sometimes in the blade side, because both have similar fatigue resistance;

- for high stress levels, i.e. $\sigma_{\max } \geq 800 \mathrm{MPa}$, cracks nucleated at the surface or subsurface (Figure 21);

- $\quad$ internal crack nucleation (Figure 22) prevailed for low stress levels, i.e. $\quad \sigma_{\max } \leq 700$ $\mathrm{MPa}$.

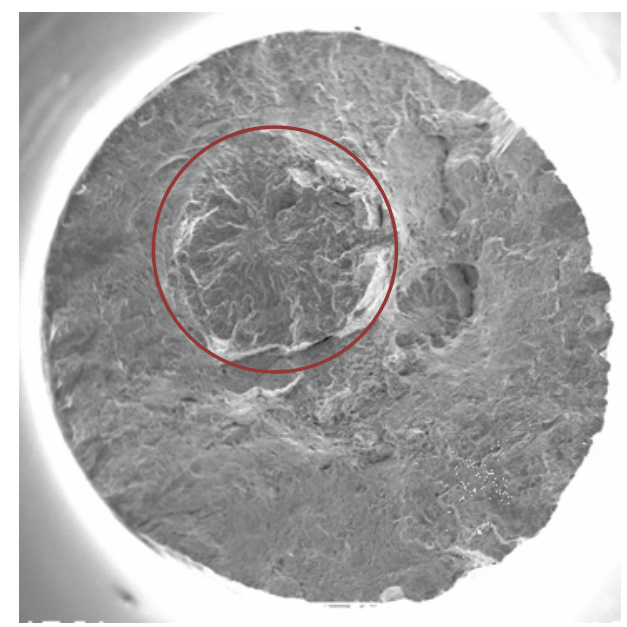

Fig. 22. Fracture surface of welded specimen tested at $\sigma_{\max }=700 \mathrm{MPa}$ and failed after $1,5 \times 10^{6}$ cycles. Circle indicates the origin of fatigue fracture.

\subsubsection{Fracture toughness}

Fracture toughness $\left(\mathrm{K}_{\mathrm{Ic}}\right)$ is a critical mechanical design parameter. Its determination was performed in both base materials and LFW samples according to the ASTM E-399 standard. Three-point-bending specimens had a section of $15 \times 15 \mathrm{~mm}$ for base materials, whereas those taken from welded joints were $10 \times 5 \mathrm{~mm}$. For the pre-craking process, a sharp pre-crack was produced in the weld plane through application of cyclic compressive loads (Corzo et al., 2007).

Fracture toughness of $\mathrm{Ti}$ alloys is very dependent on microstructural and also crystallographic characteristics. Therefore, it is hard to establish a narrow range of "typical values". From literature data (Donachie, 2000), it can be realized that $\beta$ processed alloys consistently have higher toughness than $\alpha+\beta$ processed ones. The same trend was appreciated for $\mathrm{K}_{\text {Ic }}$ values obtained for the two Ti-6246 conditions considered DUTIFRISK project, i.e. $\beta$-forged Ti-6246 specimens had higher toughness than $\alpha+\beta$-processed Ti-6246 (Table 2). This is related to the fact that the lamellar microstructure induces crack deviations and bifurcations following prior $\beta$ grain boundaries or colony boundaries (Saucer \& Lütjering, 2001). Both deviations of the mode I serve to reduce the effective near tip stress intensity factor: in the case of deviations by inducing mixed mode near tip conditions, while bifurcations disperse the strain field energy among multiple crack tips. 


\begin{tabular}{|c|c|}
\hline AAlloy & FFracture Toughness, $\left.\mathrm{K}_{\mathrm{Ic}}\left(\mathrm{MPa} \cdot \mathrm{m}^{1 / 2}\right) 2\right)$ \\
\hline$\beta$ Ti-6246 & 67 \\
\hline$\alpha+\beta$ Ti-6246 & 54 \\
\hline Weld 1 & 15 \\
\hline Weld 2 & 31 \\
\hline Weld 3 & 45 \\
\hline
\end{tabular}

Table 2. Fracture toughness testing results.

Three fracture toughness tests were performed on welded specimens. The scatter among the three $K_{I c}$ values obtained was very high, and all of them were clearly lower than those obtained for base materials. Two different behaviours can be separated. In one specimen both the fatigue pre-crack and the final fracture crack grew completely following the weld line, as shown in Figure 23. In this case, $\mathrm{K}_{\mathrm{Ic}}$ measured was the lowest one, i.e. $15 \mathrm{MPa} \cdot \mathrm{m}^{1 / 2}$; in the other two tests, crack deviations towards the heat affected zones were observed (Figure 24) and toughness values were more than double than in the previous specimen, i.e 31 and $45 \mathrm{MPa} \cdot \mathrm{m}^{1 / 2}$. From these features, it can be concluded that the "real" toughness of the weld is around $15 \mathrm{MPa} \cdot \mathrm{m}^{1 / 2}$. This low value is not surprising, because the extremely fine microstructure on the weld zone has a very high hardness, which is usually associated with a loss in toughness. The results obtained for the other specimens are in fact evaluations of the toughness of the heat affected zone, because the crack deviated to this area. Values are higher than for the weld but lower than for the base material since the affected zone microstructure is a transition between both.

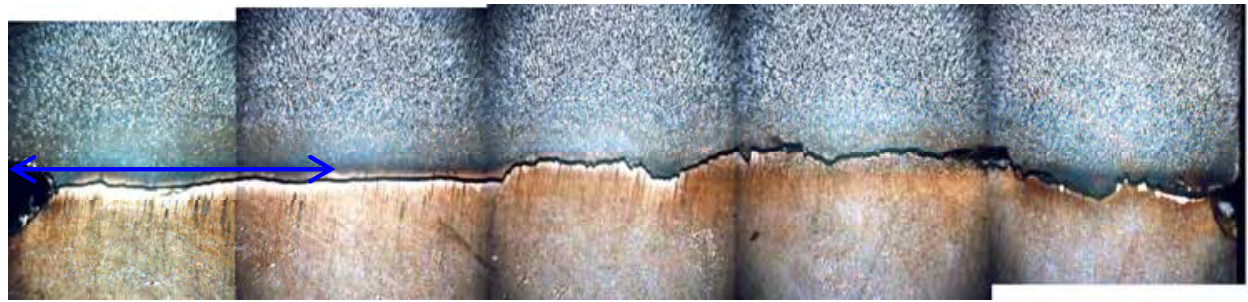

Fig. 23. Crack path for fracture toughness specimen corresponding to $\mathrm{K}_{\mathrm{Ic}}=15 \mathrm{MPa} \cdot \mathrm{m}^{1 / 2}$.

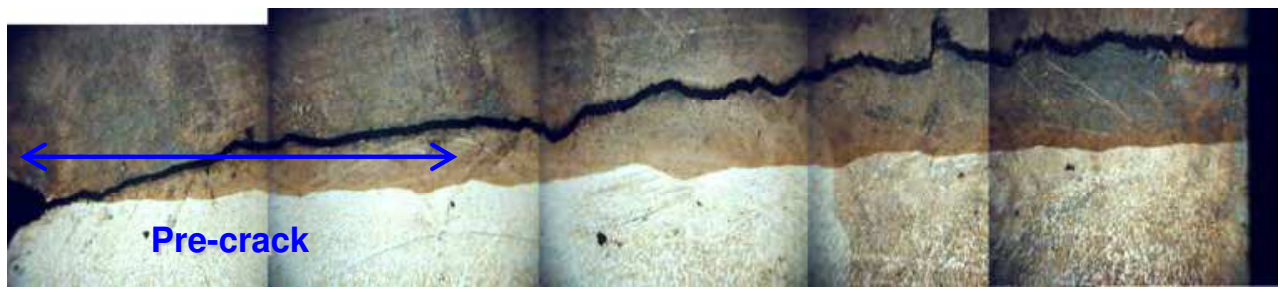

Fig. 24. Crack path for fracture toughness specimen corresponding to $\mathrm{K}_{\mathrm{Ic}}=45 \mathrm{MPa} \cdot \mathrm{m}^{1 / 2}$.

Summarizing the results of the exhaustive mechanical testing evaluation performed along DUTIFRISK project, the most relevant points are:

- Hardness values in the weld zone are very high as compared to base materials; 
- Tensile tests on microspecimens taken from the welded zone confirmed its higher strength as compared to base materials (Corzo et al., 2006);

- Tensile properties of welded samples are equivalent to those of the base material with the lowest strength, and fracture always began in that part of the specimen, never in the weld zone;

- High cycle fatigue response of linear friction welds and base materials are qualitatively similar. Failure never took place in the weld zone.

- Fracture toughness evaluation depends on the crack path: when the crack grows along the weld line low values were obtained, however when the crack deviates from the weld centre higher values were attained. Therefore, it is essential to have inspection methods to reveal even the tiniest flaws in the welds.

\subsection{Production and validation of BLISK demonstrator}

Production of BLISK demonstrators was the last work package of DUTIFRISK project. The objective was assessed and validated the relevant linear friction welding process features on a real part scale. The geometry of the disk and the blades was simplified to reduce the machining cost. In the case of the blades, they were replaced by rectangular blocks, whereas Figures 25 is a photograph of a disk for one of the demonstrators.

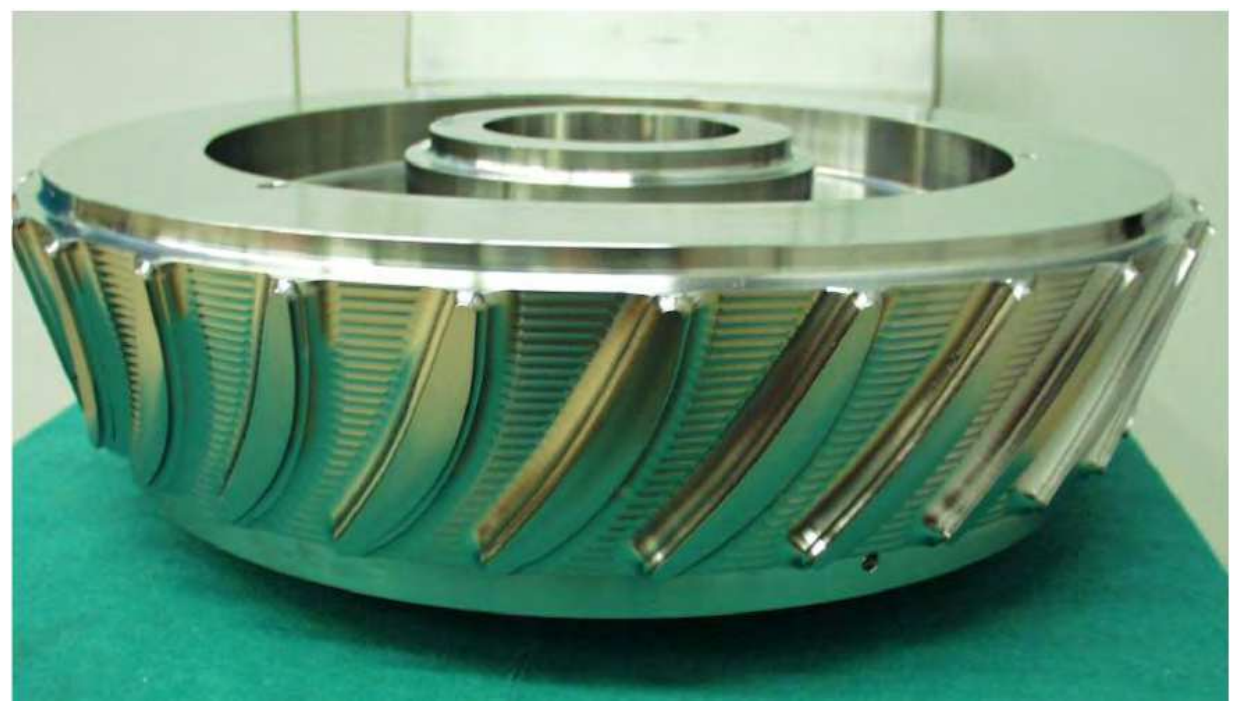

Fig. 25. Disk for BLISK demonstrator.

Linear friction welded joints of BLISK demonstrators were validated by performing microstructural characterisation and mechanical testing and comparing the results with those obtained from laboratory specimens. Consequently, after welding the blades to the disk, demonstrators were cut in order to extract blocks for machining testing specimens. Figure 26 shows the pre-machined BLISK demonstrator after extraction of blade-blocks. Those blade-blocks were post-weld heat-treated prior to the machining of the specimen blanks. Tensile and HCF tests were carried out and mechanical properties values were similar to those obtained within the normal scatter of materials data. 


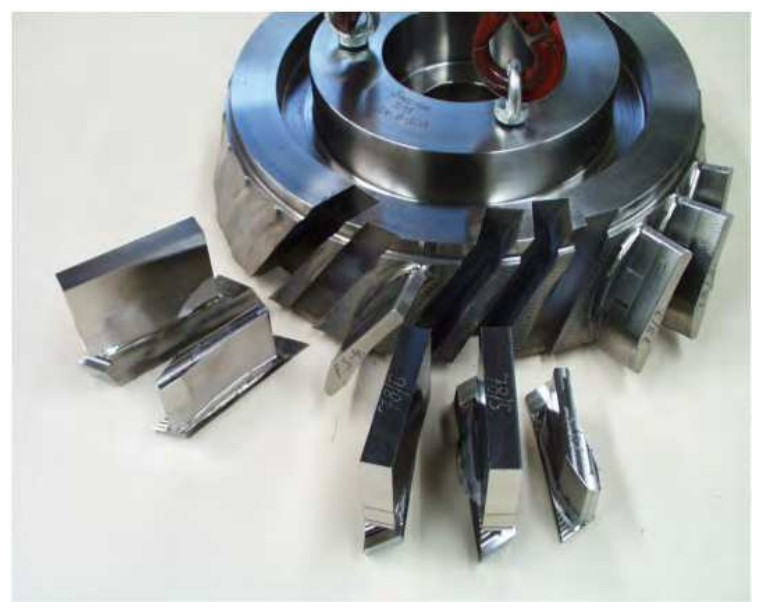

Fig. 26. Pre-machined BLISK demonstrator, after extraction of blade-blocks.

\section{Future research}

BLISK is a critical part of an aero-engine, for that reason it is obvious that the integrity and reliability of linear friction welds must be totally verified. In order to guarantee in service welds performance, more research is needed in several fields:

- Optimisation of LFW parameters for each particular combination of alloys;

- Improving the understanding of the relationship between the very fine microstructure on the weld zone and its mechanical properties, especially concerning fracture toughness;

- Development of advanced inspection techniques adapted for BLISK inspection, such as computer tomography and ultrasonic inspection, is vital to reveal defects in the welds.

On the other hand, the final customers of aero-engines will accept BLISK technology only if suitable and affordable repairing technologies are available. Damages susceptible of being repairable are similar in a BLISK and in "normal" disk + single blades configuration, with the difference that an exchange of a blade in a BLISK is not as simple as for single blades. In DUTIFRISK project, a work-package was dedicated to this topic and the conclusion was that the most convenient repairing technique is the same LFW process (Mateo et al., 2009). However, further investigations should be committed to evaluate the effect on mechanical properties of successive welds in the same area and then to establish repairing procedures.

\section{Conclusion}

The overall conclusion drawn from the industrial experiences and research activities conducted on linear friction welding of Ti alloys for BLISK manufacturing, and in particular after all the tasks carried out during DUTIFRISK project, is that it is feasible to produce, by using linear friction welding, a dual alloy/dual microstructure BLISK with a disk optimised from the viewpoint of low cycle fatigue resistance and optimised blades for high cycle fatigue. It was further proven that it is possible to join different titanium alloys, thereby allowing customising the blades according to the required temperature capability of a certain stage. 


\section{Acknowledgement}

The author of this chapter wants to recognize to all the colleagues that participated in DUTIFRISK project: J.-P. Ferte (SNECMA Moteurs), E. Gach (Böhler Schmiedetechnik), J. Méndez, J. Petit and P. Villechaise (ENSMA-CNRS), M. Nunn (TWI), M. Anglada and M. Corzo (CIEFMA-UPC) and especially to the project coordinator O. Roder (MTU Aero Engines). Also financial support of the European Commission (G4RD-CT-2001-00631, Acronym DUTIFRISK) and from the Spanish Ministerio de Ciencia e Innovación (MAT2009014461) are acknowledged.

\section{References}

Bhadeshia, H.K.D.H. \& DebRoy, T. (2009). Critical assessment: friction stir welding of steels. Science and Technology of Welding and Joining, Vol.14, No.3, pp. 193-196, ISSN 1362-1718

Bhamji, I.; Preuss, M.; Threadgill, P.L.; Moat, R.J.; Addison, A.C. \& Peel, M.J. (2010). Linear friction welding of AISI 316L stainless steel. Materials Science and Engineering A, Vol.528, No.2, pp. 680-690, ISSN 0921-5093

Broomfield, R.W. (1986). Application of advanced joining techniques to titanium alloys, Proceedings Conference on Designing with Titanium, pp. 69-75, The Institute of Metals, Bristol, UK, 1986

Bußmann, M.; Kraus, J. \& Bayer, E. (2005). An Integrated Cost-Effective Approach to Blisk Manufacturing, Proceedings of 17th Symposium on Air Breathing Engines, Munich, Germany, 4-9 September 2005

Ceschini, L.; Morri, A.; Rotundo, F.; Jun, T.S. \& Korsunsky, A.M. (2010). A Study on Similar and Dissimilar Linear Friction Welds of $2024 \mathrm{Al}$ Alloy and 2124Al/SiCP Composite. Advanced Materials Research, Vol.89-91, pp. 461-466, ISSN 1662-8985

Corzo, M.; Mendez, J.; Villechaise, P.; Rebours, C.; Ferte, J.-P.; Gach, E.; Roder, O.; Llanes, L.; Anglada, M. \& Mateo, A. (2006). High-cycle fatigue performance of dissimilar linear friction welds of titanium alloys, Proceedings of the 9th Int. Fatigue Congress, Elsevier, paper O326, CD-ROM, Atlanta, USA, 14-19 May 2006

Corzo, M.; Casals, O.; Alcala, J.; Mateo, A. \& Anglada, M. (2007). Mechanical evaluation of linear friction welds in titanium alloys through indentation experiments. Welding International, Vol.21, No.2, pp. 125-129, ISSN 0950-7116

Donachie, M.J. (2000). Titanium: A technical guide, ASM International, ISBN 0871706865, Ohio, USA

Esslinger, J. (2003). Proceedings of 10th Titanium World Conference, Ed. G. Lütjering and J. Albrecht, Wiley-VCH, Vol.V, pp. 2837-2844, ISBN 3527303065, Munich, Germany, 13-18 July 2003

External Advisory Group for Aeronautics of the European Commission (2000). Aeronautics for Europe, Official Publications of the European Communities, ISBN 92-828-8596-8, Belgium

Harvey, R.J.; Strangwood, M. \& Ellis, M.B.D. (1995). Bond line structures in friction welded $\mathrm{Al}_{2} \mathrm{O}_{3}$ particulate reinforced aluminium alloy metal matrix composites, Proceedings 4th Int. Conference on Trends in Welding Research, ASM, pp. 803-808, ISBN 0871705672, Tennessee, USA, June 5-8, 1995

Helm, D. \& Lutjering, G. (1999). Microstructure and properties of friction-welds in titanium alloys, Proceedings of 9th World Conference on Titanium, pp. 1726-1733, Saint Petersburg, Russia, 1999 
Kauzlarich J.J. \& Maurya Ramamurat R. (1969). Reciprocating Friction Bonding Apparatus. Patent Number US3420428, Caterpillar Tractor Co., 7th January 1969

Lee, W.B. \& Jung, S.B. (2004). The joint properties of copper by friction stir welding, Materials Letters, Vol.58, Issue 6, pp. 1041-1046, ISSN 0167-577X

Mary, C. \& Jahazi, M. (2006). Linear Friction Welding of IN-718 Process Optimization and Microstructure Evolution, Advanced Materials Research, Vol.15-17, pp. 357-362, ISSN 1662-8985

Mateo, A.; Corzo, M.; Anglada, A.; Mendez, J.; Villechaise, P.; Rebours, C. \& Roder, O. (2009). Welding repair by linear friction in titanium alloys, Materials Science and Technology, Vol.25, No.7, pp. 905-913, ISSN 0267-0836

Messler, R.W. (2004). Joining of materials and structures, Elsevier, ISBN 0-7506-7757-0, Oxford, U.K.

Mishra, M. \& Mahoney, M.W. (2007). Friction stir welding and processing, ASM International, ISBN 978087170848-9, Ohio, USA

Nunn, M. (2005). Aero Engine improvements through linear friction welding. Proceedings 1st Int. Conference on Innovation and Integration in Aerospace Sciences, Queen's University, Belfast, Northern Ireland, U.K., 4-5 August 2005

Roder, O.; Helm, D. \& Lütjering, G. (2003). In: Titanium'03: Science and Technology, Proc. 10th Titanium World Conference, Ed. G. Lütjering and J. Albrecht, Wiley-VCH, Vol. V, pp. 2867-2874, ISBN 3527303065, Munich, Germany, 13-18 July 2003

Roder, O.; Ferte, J.-P.; Gach, E.; Mendez, J.; Anglada, M. \& Mateo, A. (2008). Development and validation of a dual titanium alloy dual-microstructure BLISK, Proceedings 1st EUCOMAS (European Conf on Materials and Structures in Aerospace), Ed. VDI BERICHTE, ISBN 0083-5560, pp. 309, Berlin, Germany, 26-27 May 2008

Saucer, C. \& Lütjering, G. (2001). Influence of $\alpha$ layers and $\beta$ grains boundaries on mechanical properties of Ti alloy, Materials Science and Engineering A, Vol.319-321, pp. 393-397

Strand, S.R.; Sorensen, C.D. and Nelson, T.W. (2003). Proceeding Conference ANTEC 2003, Society of Plastics Engineers, Vol.1, pp. 1078-1082; Nashville, USA, 4-8 May 2003

Threadgill, P.L. (1995). Joining of a nickel aluminide alloy. Proceedings 4th Int. Conference on Trends in Welding Research, ASM, pp. 317-322, ISBN 0-87170-567-2 Tennessee, USA, 5-8 June, 1995

Threadgill, P.L.; Leonard, A.J.; Shercliff, H.R. \& Withers, P.J. (2009). International Materials Reviews, Vol.54, No.2, pp. 49-93, ISSN 0950-6608

Threadgill, P.L. (2011). Joining Linear friction welding, In: TWI web page, March 2001, Available from: http://www.twi.co.uk/content/ksplt001.html

Vairis, A. \& Frost, M. (1998). On extrusion stage of linear friction welding of Ti-6Al-4V, Wear, Vol.217, pp. 117-131, ISSN 0043-1648

Wilhem, H.; Furlan, R. \& Moloney, K.C. (1995). Linear friction bonding of titanium alloys for aeroengine applications, Proceedings of the 8th World Conference on Titanium, Ed. P.A. Blenkinsop et al., pp. 620-626, ISBN 1861250053, Birmingham, U.K., 22-26 October 1995

Wisbey, A.;Wallis, I.C.; Ubhi, H.S.; Sketchley, P.; Ward-Close, C.M. \& Thereadgill, P.L. (1999). Mechanical properties of friction welds in high strength titanium alloys, In: Titanium'99, Proceedings of the 9th World Conference on Titanium, pp.1718-1725, Saint Petersburg, Russia, 1999 


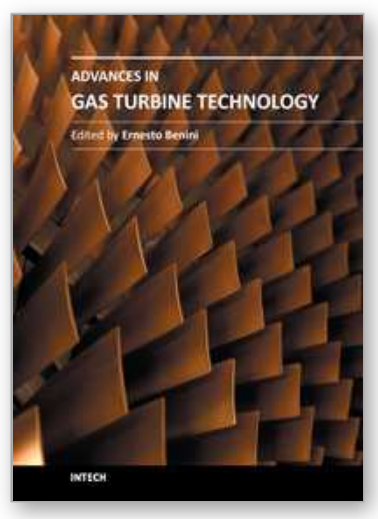

\author{
Advances in Gas Turbine Technology \\ Edited by Dr. Ernesto Benini
}

ISBN 978-953-307-611-9

Hard cover, 526 pages

Publisher InTech

Published online 04, November, 2011

Published in print edition November, 2011

Gas turbine engines will still represent a key technology in the next 20-year energy scenarios, either in standalone applications or in combination with other power generation equipment. This book intends in fact to provide an updated picture as well as a perspective vision of some of the major improvements that characterize the gas turbine technology in different applications, from marine and aircraft propulsion to industrial and stationary power generation. Therefore, the target audience for it involves design, analyst, materials and maintenance engineers. Also manufacturers, researchers and scientists will benefit from the timely and accurate information provided in this volume. The book is organized into five main sections including 21 chapters overall: (I) Aero and Marine Gas Turbines, (II) Gas Turbine Systems, (III) Heat Transfer, (IV) Combustion and (V) Materials and Fabrication.

\title{
How to reference
}

In order to correctly reference this scholarly work, feel free to copy and paste the following:

Antonio M. Mateo García (2011). BLISK Fabrication by Linear Friction Welding, Advances in Gas Turbine Technology, Dr. Ernesto Benini (Ed.), ISBN: 978-953-307-611-9, InTech, Available from: http://www.intechopen.com/books/advances-in-gas-turbine-technology/blisk-fabrication-by-linear-frictionwelding

\section{INTECH}

open science | open minds

\author{
InTech Europe \\ University Campus STeP Ri \\ Slavka Krautzeka 83/A \\ 51000 Rijeka, Croatia \\ Phone: +385 (51) 770447 \\ Fax: +385 (51) 686166 \\ www.intechopen.com
}

\author{
InTech China \\ Unit 405, Office Block, Hotel Equatorial Shanghai \\ No.65, Yan An Road (West), Shanghai, 200040, China \\ 中国上海市延安西路65号上海国际贵都大饭店办公楼405单元 \\ Phone: +86-21-62489820 \\ Fax: $+86-21-62489821$
}


(C) 2011 The Author(s). Licensee IntechOpen. This is an open access article distributed under the terms of the Creative Commons Attribution 3.0 License, which permits unrestricted use, distribution, and reproduction in any medium, provided the original work is properly cited. 